Cole, G., O’Halloran, K. and Stewart, R.A. (2012) Time of use tariffs: implications for water efficiency. Water

Science \& Technology: Water Supply 12(1), 90-100. doi: 10.2166/ws.2011.123

\title{
TIME OF USE TARIFFS: IMPLICATIONS FOR WATER EFFICIENCY
}

\author{
Graham Cole $^{1,2}$, Kelvin O’Halloran², Rodney A. Stewart ${ }^{1}$ \\ 1. Griffith School of Engineering, Griffith University, Gold Coast Campus, Australia \\ 2. Wide Bay Water Corporation, PO Box 5499, Hervey Bay, Australia \\ grahamc@widebaywater.qld.gov.au \\ kelvino@widebaywater.qld.gov.au \\ r.stewart@griffith.edu.au
}

\begin{abstract}
Water utilities undertake long term planning for water source security, often with forecast cycles of 20 to 30 years. Whilst this planning is generally involved with investigations of source water abstraction security and the need to build dams or to increase the recharge rate of groundwater aquifers, planning for water efficiency gains occurs at annual intervals. Most water utilities in Australia are heavily engaged in water efficiency initiatives with rebate schemes for domestic water-efficient devices ubiquitous across the industry. Wide Bay Water Corporation (WBWC) also engages in these activities but is increasingly interested in the concept of Time of Use Tariffs (TOUTs) to target high water users in order to reduce their demand on the system. In 2006, WBWC introduced smart metering technology across the city which captures hourly use data. Interrogation of this data has led to the ability to identify water use patterns for every domestic and commercial water customer and to design specific interventions to encourage water efficiency, such as a TOUT for domestic customers. A TOUT has been developed that imposes a penalty on all individual consumption greater than 600 litres in any hourly interval of any day in the year. The tariff was designed to reduce both the annual maximum peak hour demand. The ability to reduce both of these infrastructure design parameters may have the potential to deliver substantial savings in infrastructure planning and deployment. This paper details the design process of this tariff, examines the infrastructure savings potential derived by network modelling and explores the regulatory framework hurdles to be overcome in order to implement such tariffs in the water industry.
\end{abstract}

Key Words: efficiency, peak demand, water demand management, water tariffs.

\section{BACKGROUND}

\section{Components of domestic water consumption}

Residential water use in Australian urban areas has traditionally included a significant outdoor component and various studies have been undertaken to measure indoor and outdoor use as distinct components. A number of domestic water end use studies have been conducted in Australia and internationally over the last decade (Mayer et al. 1999; Loh and Coghlan, 2003; Roberts, 2005; Willis et al. 2009; Willis et al. 2010a; Beal et al. 2011b). End use studies such as these provide greater understanding on the water consumption demand of various end uses, including outdoor, and their likelihood at various times of the day. They can also provide very detailed relationships between attitudes and water end use (Willis et al. 2011b), recycled water source substitution and end uses (Willis et al. 2011b), behaviour 
interventions and water end uses (Willis et al. 2010b; Stewart et al. 2011), to name a few benefits of high resolution smart metering (Stewart et al. 2010).

The type of data provisioned by water end use studies is particularly useful to aid the unpacking of peak demand to reveal what hourly each interval volume of water will comprise.

Consumption in most states of Australia has declined over the past 10 decades or so because of restrictions, water saving devices and consumer education associated with a long and severe drought. This is reflected in the lower overall consumption values in the more recently reported Gold Coast and South East Queensland end use studies. However, the lion's share of the reduced overall domestic consumption resulted from significantly lower irrigation demand.

\section{Diurnal patterns and peak demand}

Residential water use reflects the pattern of daily life and there is a morning and afternoon peak demand period where the highest consumption occurs during each 24 hour period. Domestic water demand has been succinctly defined by MacDonald (2007) as the interaction of three cycles plus some semi random perturbations. The first cycle is the daily life cycle revolving around work, school, etc. The second cycle is the variation attributable to weekend activities and the third cycle is the annual progression of the seasons and their influence on water use. The semi random perturbations are the influence of weather and consumer education and conservation on water use.

People generally use the toilet, shower, have breakfast and clean their teeth before leaving for work or school and the whole pattern is more or less repeated in the afternoon when they arrive home (Kappel \& Grechenig, 2009). The term 'peak demand' in this context refers to the consumption which occurs during peak periods. Water distribution pump, pipe and storage infrastructure is designed to provide minimum service standards for these periods, thus reductions in peak demand may have potential to save significant capital and operational expenditures. Typical daily diurnal demand patterns for week days vary from those for weekend and public holiday periods (Alvisi et al. 2007). This reflects changes in routine associated with these periods.

The way most people think about the term peak demand is reflected in the definitions most often applied, something along the lines of 'highest demand during a peak period for goods or services' is usually quoted. However the terms peak demand consumption, peak hour, peak supply and other permutations are often used interchangeably to such an extent as to be confusing. For the purpose of this study, the following definitions have been taken from the Glossary of Terms in Planning Guidelines for Water Supply and Sewerage produced by the Queensland Department of Environment and Resource Management, p3. (2010):

- Peak hour demand: Peak hourly demand a system will be called on to deliver.

- Peak day demand: Maximum demand in any one day of the year.

Managing peak demand is essentially about reducing or at least putting constraints on the growth of future demand and capping the cost of infrastructure (Brooks, 2006). Water demand management is defined by (Brooks, 2006) as the development and implementation of strategies aimed at influencing demand, so as to achieve efficient and sustainable use of a scarce resource. Savenjie and van der Zaag (2002) argue that peak demand management should be a primary component of any overall water demand management strategy. 
The obvious implication of the variability of hourly water demand lies in the effect on the means of supply, i.e. the water distribution network from the supply reservoir onwards must be adequately sized to accommodate peak hour demand. This is particularly so in areas of high population growth where increased demand for water supply parallels the increase in the number and density of new housing estates, inevitably leading to the construction of new reticulation pipelines and eventually the upgrading of trunk mains (Brooks, 2006).

\section{Economic benefits from reduced peak hour demand}

In water supply systems, water mains are sized to meet storage and consumption demands according to existing customer service standards plus fire flows (which is a legislative or moral obligation). Trunk mains from the reservoir and reticulation mains are designed to carry the necessary flow to meet the highest hourly peak consumption expected to occur in the course of a year. Reduced peak flow will create spare capacity in the existing reticulation infrastructure.

The following points are the central conclusions of a hydraulic modelling investigation conducted for an existing Hervey Bay District Metered Area (DMA) to model the effects of a 20 per cent reduction in peak hour demand and to estimate the resulting capital cost savings:

For the existing demand scenario, a negligible improvement in infrastructure sizing and capital costs was achieved (i.e. $\$ 22,000$ over a total of $\$ 6.3$ million). This was due to the design requirements of the fire flow provisions 'outweighing' the total flow rate difference between peak hour and 20 per cent reduced peak hour (i.e. 16 litres).

For the Planning Scheme Demand (PSD) demand scenario, significant improvements in infrastructure sizing and capital costs were achieved (i.e. $\$ 230,000$ over $\$ 7$ million). In comparison to the existing demand scenario, this improvement was predominantly due to the separation between the current and 20 per cent reduced peak hour demand being significant enough to overcome fire flow design requirements.

Residual capacity of the existing network was significantly improved. Approximately 650 additional Equivalent Dwelling (ED) to the existing 2,730 ED was achieved before compromising the relevant design provisions. This equates to a potential increase in water revenue of $\$ 160,000$ per annum for the Point Vernon DMA examined.

Readers should note that the network solutions determined from the investigation are indicative only and were completed solely for the purpose of providing preliminary evidence to support the view that TOUTs have potential water supply system capital efficiency benefits. While the herein findings are tentative and apply specifically to this situational context (i.e. one DMA in Hervey Bay) they nonetheless present evidence that reducing peak hour demand will create spare capacity in a reticulation network (23.8 per cent more in the model above). If this spare capacity can be used to supply additional properties, for example in infill developments, there may be scope to defer trunk or reticulation main upgrades that would have otherwise been required to meet the specific DMA PSD.

\section{Domestic water use price elasticity}

According to Shu Fan and Hyndman (2008) there are two types of price elasticity-own price elasticity, and substitution elasticity. The latter type is more appropriate to a TOUT context. Specifically, if the price of electricity varies substantially from one time period to another and 
customers can shift usage among those periods, then the appropriate measure of price response is how relative usage changes in those periods.

The substitution elasticity is therefore defined as the relative change in usage in the two periods (e.g. the ratio of the peak to off peak usage) for a one percent change in the relative prices in those periods (the ratio of the off-peak to peak price). Note that the price term uses the inverse price ratio which is why substitution elasticities are positive (e.g. a higher peak price decreases the off peak to peak price ratio, causing peak load to be reduced and therefore the peak to off peak load ratio to decline). Substitution elasticity estimates for domestic water consumption are lacking in the literature. The following price elasticity estimates have been based on own price elasticity.

Table 1 presents a summary of reported price elasticity estimates for domestic water use in Australia (Arbués et al. 2003; Martínez-Espiñeira and Nauges, 2004, Hoffman et al. 2006;). Some price elasticity estimates accounted for seasonal differences (e.g. summer and winter) and/or usage type (e.g. outdoor and indoor).

\section{[INSERT TABLE 1]}

Hoffman et al. (2006) constructed a model for estimating short and long term price elasticities and predicted an apparent increase in price elasticity for water over time after a price increase. Nataraj (2007) suggested that a likely reason for this increase in price elasticity of water over time is that customers become accustomed to the price change and change their usage patterns accordingly. According to Nauges and Thomas (2003) it may take a year or more for consumers to start responding to price change.

Overall there seems to be little consensus in current literature on the price elasticity of various types of water use except that outdoor usage is considered more elastic than indoor usage and ultimately, price elasticity is linked to a customer's behavioural responses and socio-economic characteristics (Jorgenson et al. 2009) as well as other influences such as weather and temperature (Boland, 1997). Estimates of consumption components by volume also varied according to local influences including the presence and/or duration of water restricitions and the climate. The best estimate is that at least 50 per cent of consumption regardless of circumstance is indoor consumption; it is the outdoor component that varies most according to local influence.

\section{RESEARCH OBJECTIVES}

The overarching goal of the research was to develop a feasible TOUT to reduce peak hour demand. Specific objectives are detailed below:

1. determine the hourly volumetric (L) demand for combinations of common domestic water end use events

2. estimate the price elasticity of water outdoor water end use

3. design an equitable tariff to target the discretionary component of peak hour consumption.

These objectives are addressed in the tariff design section following. 


\section{TARIFF DESIGN RESEARCH FINDINGS}

\section{Study sample}

The implementation of a smart metering system in Hervey Bay, beginning late 2006, represented a milestone for the Australian water industry because for the first time a water utility in this country could record the water consumption of all its customers by the hour. The availability of this significant data repository provided a research opportunity to analyse a full year (July 2008 to June 2009) of hourly data from 3,151 customers, including 2,884 residential customers in spread over 4 DMAs in Hervey Bay, and research the possibilities of using TOUTs as a tool to reduce peak hour water demand.

\section{Identifying customers contributing to peak demand}

Analysis showed that 217 of the residential customer connections were responsible for over half the total volume of water used during the peak hour of the peak day (i.e. 29 December 2008) and that 37.78 per cent of all peak hour consumption (including commercial use) consisted of use by residential users at volumes greater than 600 litres. It is reasonable to assume that this is predominantly outdoor use.

As outdoor use is considered the most price elastic component of domestic water use, it would seem the best solution to reducing peak hour demand is to target outdoor use during peak periods. The fact that this high outdoor component comes from a very small minority of the 2,884 residential customers in the study has lesser social equity implications than tariff structures that may target all water end use categories. There is also enough scope to achieve a 10 per cent reduction in annual maximum peak hour consumption solely by targeting and shifting discretionary outdoor use.

\section{Designing tariff that targets high outdoor use}

The first tariff to consider is the traditional TOUT which comprises a higher charge applied during peak periods and a much lower off-peak charge designed to entice consumers to shift consumption from peak periods to off peak periods. There may be a shoulder charge applied to the hour either side of the peak period which is designed to discourage consumers from concentrating consumption in these hours.

There are, however, two fundamental issues with a traditional TOUT. First, a peak charge is usually applied to all consumption during the peak period, including non-discretionary water use; this would affect the 90 per cent of residential consumers who did not contribute to peak hour demand with discretionary water use. It is difficult to justify a tariff which targets nondiscretionary uses when discretionary use by a small number of consumers constitutes such a significant proportion of peak hour demand.

Secondly there is a risk that the combination of a peak, shoulder and off peak charge could concentrate outdoor consumption in shorter periods and thus serve to create alternative peaks. The risk is difficult to quantify and can really only be tested by a trial implementation of a TOUT.

A traditional type TOUT does not seem appropriate given that it would target the nondiscretionary consumption of such a large proportion of consumers. An alternative tariff is needed which specifically targets high outdoor consumption in peak periods; this can only be 
achieved by targeting the consumption volume ranges which were modelled to be largely outdoor use.

In effect, a tariff penalising water usage which exceeds a specific threshold volume within each hour. This tariff would include increased charges for all consumption over a certain volume in an hourly interval and could be applied during specific hours across all hours; it is essentially an hourly inclining block tariff.

\section{Who pays the penalty?}

The peak period on the date of the annual peak hour (29 December 2008) extended from 17:00 through to 21:00 in the evening, a total of four hours. A total of 202 different customers in the study sample used water at volumes greater than 600 litres per hour during the peak period from 17:00 to 21:00 and the time these customers spent watering varied from one to four hours. Of these, a total of 15 customers irrigated for four hours; 19 irrigated for three hours; 60 for two hours and 108 for one hour.

Further analysis of the water use of all 2,884 residential connections in the study sample over the full year showed that a small group of customers were responsible for a high proportion of consumption in volumes above 600 litres per hour. Table 2 shows a breakdown of the number of hours with events having water use volumes that were greater than 600 litres per hour for the period 1 July 2008 to 30 June 2009 (one year period). For example, the first row of Table 4 shows 1,542 customers used water in volumes greater than 600 litres per hour for between one and 50 hours each for the whole year. This consumption was recorded by this group for a total of 22,066 hours, giving a total volume of 18,779 kilolitres at an average rate of 852 litres per hour.

Of the 2,884 residential connections in the study group, 1,905 recorded water use in volumes greater than 600 litres per hour at least once. Some 979 residential customers, or 33.94 per cent of all residential connections in the study group, did not once record water use in volumes greater than 600 litres in any hour for the whole year.

\section{[INSERT TABLE 2]}

Only 162 connections or 5.61 per cent of the total number of residential connections, recorded volumes greater than 600 litres per hour for more than 100 hours in the one year study period. This group was responsible for 49.57 per cent of all consumption greater than 600 litres per hour during this period and is the logical target of a penalty tariff that has the most potential to reduce peak hour demand.

\section{Determining a volumetric penalty charge}

A volumetric penalty could initially be premised on the best available price elasticity estimates for water consumption, particularly as there is no precedent or experience to base an estimate relevant to the target group. Clearly no price elasticity research has been done in Hervey Bay; however work has been done recently in Brisbane, a similar sub-tropical location, by Hoffman et al. (2006). This study of consumption data from various suburbs across the city arrived at a price elasticity figure of 0.507 for overall consumption; unfortunately an extensive search of the literature produced no recent price elasticity figure for outdoor use in Brisbane. The outdoor component may well have higher elasticity but this is the only documented figure available to derive a penalty charge which is both recent and from a location relatively close to Hervey Bay. 
It may also be argued that, despite all the circumstantial evidence put forth so far supporting the hypothesis that consumption greater than 600 litres per hour is predominantly outdoor use, we do not really know for certain what the proportion of outdoor and indoor usage is within that volume range and therefore a price elasticity figure for overall water use is more appropriate.

Residential use in volumes greater than 600 litres per hour comprises 37.78 per cent of total peak hour demand. Achieving a 10 per cent reduction in total peak hour demand by targeting just residential use greater than 600 litres per hour requires a reduction in the volume of this category of use by 26.46 per cent. To find an appropriate penalty charge for either a time of use or hourly inclining block tariff we rely on the formula to calculate price elasticity and work backwards from the existing tariff of $\$ 1.37$ per kilolitre using a 26.46 per cent reduction in demand.

The equation to find the percentage (\%) change in price required to achieve a 10 per cent reduction in overall demand is thus:

$\mathrm{P}=(-26.46$ divided by -0.507$)$

$\mathrm{P}=52.19$

The change in price is therefore 52.19 per cent of the standard tariff of $\$ 1.37$ and we arrive at a proposed penalty tariff charge of $\$ 2.08$ per kilolitre.

Given the criteria of targeting specific consumption greater than 600 litres per hour, there are two basic approaches available: (1) impose the penalty tariff during specific hours of the day; or (2) impose 24 hour coverage. Specific tariff models examined in this study are explored below.

\section{Examined tariff models}

Three tariff models were examined to target peak demand as follows:

- Tariff model 1: a penalty applied during peak period hours 17:00 to 21:00 only

- Tariff model 2: a penalty applied across all hours except the low demand early hours of the morning (i.e. 0:00 to 7:00)

- Tariff model 3: a penalty applied across all hours of the day.

All three models are shown superimposed on an hourly consumption table of the peak day as an example of application. No assumptions were made on whether consumption may have shifted as a result of each model. Table 3 details the Tariff Model 1 findings. Specifically, this table details outcomes of a model that applies a peak charge to all residential consumption greater than 600 litres per hour during peak periods (i.e. 17:00 to 21:00) of the maximum day (i.e. 29 December 2008). The boxed cells highlight the time the penalty applies and the consumption targeted. There is much uncertainty about the consumer response to this model as the targeted consumption may not redistribute evenly; it is possible that many customers may begin watering immediately after the peak charge has been lifted at 21:00 and thus simply move the peak in time; but this is the simplest tariff to understand and apply.

[INSERT TABLE 3] 
Table 4 details the Model 2 Tariff. This tariff has the peak charge applied discriminately to consumption over 600 litres per hour during the 7:00 until 24:00 period. There is no off peak rate and the standard tariff of $\$ 1.37$ per kilolitre applies to all consumption not subject to the excess consumption penalty. This model has the benefit of targeting a significant level of consumption in the greater than 600 litres per hour category during the 7:00 to 17:00 period. It also prevents shifting outdoor use to the period from 21:00 till 24:00.

If customers want to irrigate with volumes greater than 600 litres per hour they can do so during the period from 0:00 to 7:00 and avoid the peak tariff. With this tariff structure, there is still the possibility that the small number of very large users could start irrigating at the same time during the early hours when the penalty does not apply and create early morning peaks; however any such peak would be much lower than the peak hour demand as there is very little usage at lower volumes during the early morning hours..

\section{[INSERT TABLE 4]}

The third penalty tariff model is based on applying the \$2.08 per kilolitre penalty tariff to all consumption in excess of 600 litres across all hours of the day (Table 5). Table 5 presents the findings of the tariff application applied to all residential consumption greater than 600 litres per hour during annual maximum peak day (i.e. 29 December 2008). All other consumption is charged at the standard tariff rate of $\$ 1.37$ per kilolitre. This tariff is based on the assumption that an excessive consumption penalty charge will encourage all consumers to keep consumption rates at or under 600 litres per hour. The 24 hour penalty tariff is less likely to create alternative peaks because the penalty charge is applied during all hours of the day. However, it has one significant disadvantage. With the two previous models, consumers did not need to know when they were exceeding 600 litres per hour because they had the option of simply avoiding irrigation during the period the penalty applied. Under the 24 hour model householders using water indoors and outdoors simultaneously would have no idea how much water was used overall in an hourly period.

\section{[INSERT TABLE 5]}

\section{Predicting shifts in consumption}

Predicting customers' responses to a peak charge is very difficult; there is no way of knowing if all targeted consumption may not reappear over a very short time during periods not subject to a penalty charge. A conservative basis for predicting the maximum number of consumers likely to use water outdoors during any one hour period can be gained by looking at the previous consumption patterns.

A conservative basis for predicting the maximum number of consumers likely to use water outdoors during any one hour period can be gained by looking at the number of consumers using water in volumes greater than 300 litre per hour during the peak hour.

There were 227 consumers using water at volumes greater than 300 litres per hour during peak hour. The average volume was 684 litres per hour. Total volume of usage greater than 300 litres per hour was 153,930 litres. The total consumption during peak hour was 238,340 litres.

Highest consumption for volumes in the range from 10 to 300 litres per hour in the early hours of the peak day was 36,450 litres between 6:00 am and 7:00am. If the 153,930 litres of 
peak hour outdoor was shifted to 6:00 am in the morning the total consumption during that hour would have been 190,380 litres, almost 48,000 litres less than the actual peak hour.

The first tariff model is more likely to result in an alternative evening peak because the penalty period ends at 21:00 and some consumers could still be expected to begin using water outdoors at that time. It is unlikely that these potential peaks could be as large as the annual peak hour because it is expected that at least some outdoor use would be spread over different hours and there is much less non-discretionary consumption during the late night or early morning hours. The only way of discovering if shifting outdoor use would create alternative peaks is through a trial implementation of a tariff similar to that proposed here.

\section{Technical limitations affecting tariff design}

One problem in particular with the 24 hour tariff (i.e. Tariff Model 3) is the lack of any means for the consumer to monitor consumption; how does one know when one is using more than 600 litres per hour? What happens if there are multiple users within the house at the same time? Consumers would need to have some means of monitoring consumption to ensure they were able to keep it under 600 litres per hour. With the peak and day/night versions of the tariff the issue is not as critical, as consumers can choose to irrigate at times the penalty does not apply.

A second issue concerns an overlap between measured hourly periods if water use begins at half past the hour. This arises from the necessity of the presently installed smart metering technology to measure water use from the top of each hour rather than measuring water use over any hourly period. Peak hour demand to the reticulation network occurs not necessarily during the hour from 19:00 until 20:00 but over any hour period. It may be from 18:30 until 19:30. The instantaneous peak is that point in time when the highest flow rate is experienced.

Recording consumption from the top of the hour, as the smart meters are programmed, creates an opportunity for customers to alter the timing of their outdoor use to avoid at least part of any penalty tariff. For example, if a customer starts sprinkling at 16:30 and leaves it running for one hour at a flow rate of 1200 litres per hour, the Firefly logger will record 600 litres in the hour from 16:00 to 17:00 and 600 litres in the hour from 17:00 to 18:00.

Although using 1200 litres in a one hour period, this customer has effectively avoided the penalty charge. However, if the sprinkler was left running for two hours then 1200 litres would be recorded in the hour from 17:00 to 18:00 and the penalty charge would be incurred. The customer can only avoid the penalty charge once if using water for more than one consecutive hour. Of course the customer can totally avoid the penalty charge if beginning watering at the bottom of the hour (i.e. at half past the hour) and watering every second hour. A traditional TOUT does not suffer from this problem as the peak and off peak charges apply to defined hourly periods. Any consumption occurring during each hour during peak periods must be measured from the top of the hour. As a final note here, future smart metering technology will likely be able to overcome these described technical issues as it will be able to monitor running hourly intervals to capture use greater than 600 litres per hour (i.e. 18:42 to 19:42 instead of set hourly intervals).

\section{Designing an equitable tariff}

The result of a hypothetical penalty tariff based on $\$ 2.08$ per $\mathrm{kL}$ and imposed on all consumption greater than 600 litres per hour over the period July 2008 to June 2009 (i.e. one year) is shown in Table 6. This table presents the findings from the modelled implementation 
of a hypothetical penalty charge applied to study group customers using volumes greater than 600 litres per hour for the year 1 July 2008 to 30 June 2009.

The seven customers using water at high rates for more than 500 hours per annum would have each been billed on average an extra $\$ 620.44$ over the year. Of the total 1,905 customers who used water greater than 600 litres per hour during the course of the year, 1,542 or 80.94 per cent paid extra charges of only $\$ 7.50$ each. This supports the choice of some form of hourly inclining block tariff as the fairest and most appropriate pricing signal to manage peak hour demand for this study group. It only targets the disproportionately high consumption of a small number of customers.

\section{[INSERT TABLE 6]}

Whether applied all year round or restricted to peak periods, the tariff only has significance for the 162 large water users who constitute just 5.61 per cent of all residential customers in the study. Note also that these 162 customers were responsible for 49.57 per cent of all residential water use at volumes greater than 600 litres per hour. This simple but effective tariff design does not penalise the majority of domestic water consumers, who would be much more affected by a traditional TOUT where the peak period charge would apply to all volumes of discretionary and non-discretionary consumption.

As the goal is to target discretionary water use, the fairest and probably least difficult method would be a combination of time of use and inclining hourly block tariff such as Table 4 (Tariff Model 2) which applies a penalty charge to the period 7:00 to 12:00 leaving the early morning hours free of penalty to attract outdoor use. In this case consumers would not need to worry about whether they were exceeding 600 litres per hour during the hours when the penalty applied; by avoiding outdoor use during the penalty period they could be sure they were not exceeding the 600 litres per hour threshold.

Other alternatives include reducing the threshold for the peak penalty to 400 litres or even 300 litres during peak periods. This would have the added benefit of reducing the effect of the hourly overlap issue identified above and ensuring no outdoor use takes place during peak periods.

A traditional TOUT is not suitable on the basis that it would adversely impact and inconvenience the great majority of customers who do not contribute to peak hour demand with discretionary water use. On the other hand a tariff applied to consumption above a certain threshold on an hourly basis has a lot of merit as it would only affect what is reasonably assumed to be outdoor discretionary consumption.

Therefore the tariff was designed on the basis of the existing two-part tariff but to have an hourly inclining block for the volumetric component. The existing charge of $\$ 1.37$ per kilolitre could apply to all consumption up to 600 litres per hour and the higher \$2.08 per kilolitre penalty charge could be applied to all consumption over 600 litres per hour.

The tariff has inherent flexibility as the penalty charge may be applied only during certain hours of the day and/or on a seasonal basis. This flexiblility also makes the tariff ideal as an alternative to water restrictions during times of drought. The penalty component targeting outdoor consumption could be raised appropriately without affecting non-discretionary 
consumption or the penalty threshold could be reduced from 600 litres per hour during serious water shortages.

\section{CONCLUSIONS}

In summary we have examined a number of fundamental aspects of tariff reform, including price elasticity, components of domestic water consumption, and tariff design. Examination of these aspects leads to an understanding of the type of tariff that is likely to be the most effective in driving water efficiency and reducing peak demand.

The key to an effectively priced TOUT, and the general consensus in the literature, is that outdoor water use is more price elastic than indoor use. This was to be expected as outdoor use is essentially discretionary. However, there may be significant variation in price elasticity for various types of indoor usage; personal hygiene may be the most price inelastic of all water usage (Kappel and Grechenig, 2009) whereas water use for dish washing and washing machines may be postponed to the off peak period by many consumers.

Moreover, the literature indicates that the price elasticity for outdoor use is somewhere between ${ }^{-} 0.7$ and ${ }^{-} 1.45$ and for indoor use somewhere between ${ }^{-} 0.04$ and ${ }^{-0} 0.94$. This variation may be accounted for by location, climate, water restrictions, season, socio-economic and other factors. A TOUT would therefore be most effective where residential outdoor consumption remains a significant proportion of overall consumption.

The proportion of total peak hour water consumption that could be attributed to residential outdoor use was determined in this study as 37.48 per cent. Since outdoor use is considered the most price elastic of domestic water consumption there is ample scope for reducing peak hour consumption with a tariff targeting outdoor use.

An hourly inclining block penalty tariff which targets outdoor consumption seems the most efficient way of reducing peak hour demand and is probably the fairest tariff when considering all socio-demographic groups covering all water consumers. The proposed volumetric penalty charge was calculated on the basis of the most recent estimate of price elasticity of overall water use in Brisbane, Queensland, Australia (Hoffman et al. 2006). Based on a price elasticity of ${ }^{-} 0.507$, a penalty charge was calculated at $\$ 2.08$ per kilolitre for every litre over 600 litres to achieve a 10 per cent reduction in overall peak hour demand.

Of the three penalty tariff hourly inclined block models considered, two targeted specific hours of the day and the third is applied 24 hours of the day. These three models demostrate the concept of an hourly threshold penalty level on an application sample of customers. There are many other permutations of this tariff design that could be devised to meet almost any circumstance. The key variables that can be modified to create alternative tariffs are the threshold level at which the penalty applies, time period the penalty charge is applied, and the rate of penalty charges applied. The herein described domestic tariff can thus meet both short and long run marginal pricing requirements as well as act as an alternative to water restriction regimes, thereby avoiding the community costs inherent in water restrictions.

ACKNOWLEDGMENTS

Mr Cole would firstly acknowledge the National Water Commission for providing the funding and support to make this research possible. The research team also acknowledges Mr. Joshua May from H2One Pty. Ltd. for his network modeling work, the study sample 
customers, and Wide Bay Water Corporation for providing the data necessary to undertake this research.

\section{REFERENCES}

Alvisi, S., Franchini, M. \& Marinelli, A. 2007, 'A short-term, pattern-based model for water demand forecasting’, Journal of Hydroinformatics, vol. 9, no. 1, pp. 39-50.

Arbués et al. 2003;

Boland, J. J. 1997, 'Assessing urban water use and the role of water conservation measures under climate uncertainty’, Climatic Change, no. 37, pp. 157-176.

Beal, C., Stewart, R.A., Huang, T.T., Rey, E., 2011b. SEQ residential end use study. Journal of the Australian Water Association. 38(1), 80-84.

Brooks, D.B. 2006, 'An operational definition of water demand management', International Journal of Water Resources Management, vol. 22, no. 4, pp. 521-528.

Department of Environment and Resource Management 2010. Planning Guidelines for Water Supply and Sewerage,p.3.

Fan, S. \& Hyndman, R. 2008, 'The price elasticity of electricity demand in South Australia and Victoria’, Business \& Economic Forecasting Unit, Monash University, Victoria.

Hoffman, M., Worthington, A. \& Higgs, H. 2006, 'Modelling residential water demand with fixed volumetric charging in a large urban municipality: the case of Brisbane, Australia', The Australian Journal of Agricultural and Resource Economics, vol. 50, no. 3, pp. 347-359.

Jorgenson, B., Graymore, M. \& O'Toole, K. 2009, 'Household water use behavior: An integrated model’, Journal of Environmental Management, no. 91, pp. 227-236.

Kappel, K. \& Grechenig, T. 2009, 'Show-Me: Water consumption at a glance to promote water conservation in the shower', in Proceedings of the 4th International Conference on Persuasive Technology, no. 350, pp. 1-6.

Loh, M. \& Coghlan, P. 2003, 'Domestic Water Use: In Perth, Western Australia', Water Corporation, Perth, Australia.

Macdonald, A. 2007, Chapter 2 'Water Needs: The Demand for Water', Sustainable Water: Chemical Science Priorities, Royal Society of Chemistry Report, p.11, PDF viewed 17 February, 2010.

http://www.rsc.org/scienceandtechnology/policy/documents/water.asp

Martínez-Espiñeira, R. \& Nauges, C. 2004, 'Is all domestic water consumption sensitive to price control?’ Applied Economics, no. 36, pp. 1697-1703.

Mayer, P.W., DeOreo, W. B., 1999. Residential End Uses of Water. Boulder, CO. Aquacraft, Inc. Water Engineering and Management. 
Nataraj, S. 2007, 'Do residential water consumers react to price increases? Evidence from a natural experiment in Santa Cruz', Agricultural and Resource Economics Update, vol. 10, no. 3, pp. 9-11.

Nauges, C. \& Thomas, A. 2003, 'Long-run study of residential water consumption Environmental and Resource Economics, no. 26, pp. 25-43.

Roberts, P., 2005. Yarra Valley Water 2004 Residential End Use Measurement Study. Melbourne. Yarra Valley Water.

Savenjie, H. H. G. \& van der Zaag, P. 2002, 'Water as an economic good and demand management: Paradigms and pitfalls’, Water International, vol. 27, no.1, pp. 98-104.

Stewart, R.A., Willis, R.M., Giurco, D., Panuwatwanich, K., Capati, G., 2010. Web based knowledge management system: linking smart metering to the future of urban water planning. Australian Planner, 47 (2), 66-74.

Stewart, R.A., Willis, R.M., Panuwatwanich, K., Sahin, O., 2011. Showering behavioural response to alarming visual display monitors: Longitudinal mixed method study. Journal of Behaviour and Information Technology. 10.1080/0144929X.2011.577195

Willis, R., Stewart, R., Panuwatwanich, K., Capati, B. \& Giurco, D. (2009) Gold Coast Domestic Water End Use Study. Journal of Australian Water Association, 36(6), 79-85.

Willis, R.M., Stewart, R.A., Panuwatwanich, K., Jones, S., Kyriakides, A., 2010a. Alarming visual display monitors affecting shower end use water and energy conservation in Australian residential households. Resources, Conservation and Recycling. 54(12), 1117-27.

Willis, R.M., Stewart, R.A., Emmonds, S., 2010b. Pimpama-Coomera dual reticulation end use study: pre-commission baseline, context and post-commission end use prediction. Water science and technology: water supply. 10(3), 302-14.

Willis, R.M., Stewart, R.A., Panuwatwanich, K., Williams, P.R., Hollingsworth,A.L., 2011a. Quantifying the influence of environmental and water conservation attitudes on household end use water consumption. Journal of Environmental Management. 92(8), 1996-2009.

Willis, R.M., Stewart, R.A., Williams, P., Hacker, C., Emmonds, S., Capati, G., 2011b. Residential potable and recycled water end uses in a dual reticulated supply system. Desalination. 272(1-3), 201-211. 
Table 1: Reported price elasticity ranges for urban water use in Australia

\begin{tabular}{lll}
\hline Location & Characteristics & Estimated price elasticity \\
\hline \multirow{2}{*}{ Adelaide } & Winter & -0.29 to -0.45 \\
& Summer & -0.69 to -0.86 \\
& All Year & -0.63 to -0.77 \\
\hline \multirow{2}{*}{ Australia } & Winter & -0.04 to -0.36 \\
\hline \multirow{2}{*}{ Brisbane } & Summer & -0.30 to -1.20 \\
\hline \multirow{2}{*}{ Perth } & Not specified & -0.55 to -0.67 \\
\hline Sydoor & Outdoor & -0.04 \\
& Total & -0.31 \\
& Indoor & -0.18 \\
\hline
\end{tabular}

Table 2: Number of hours of consumption greater than 600L/hr for the one year study period

\begin{tabular}{lrr}
\hline Hours of use categories & No. of connections & Total hours recorded \\
\hline $1-50$ & 1,542 & 22,026 \\
$51-100$ & 201 & 14,228 \\
$101-150$ & 73 & 8,787 \\
$151-200$ & 41 & 7,027 \\
$201-250$ & 20 & 4,366 \\
$251-300$ & 6 & 1,634 \\
$301-350$ & 6 & 1,921 \\
$351-400$ & 4 & 1,462 \\
$401-450$ & 2 & 838 \\
$451-500$ & 3 & 1,452 \\
$>500$ & 7 & 4,275 \\
\hline Totals & $\mathbf{1 , 9 0 5}$ & $\mathbf{6 8 , 0 1 6}$ \\
\hline
\end{tabular}


Table 3: Tariff Model 1 water consumption distributions

\begin{tabular}{crrrr}
\hline $\begin{array}{r}\text { Time of day } \\
\mathbf{( 2 4} \mathbf{~ h r})\end{array}$ & $\begin{array}{r}\mathbf{1 0 - 1 0 0 L} / \mathbf{h r} \\
\mathbf{( L )}\end{array}$ & $\begin{array}{r}\mathbf{1 0 0}<=\mathbf{3 0 0 L} / \mathbf{h r} \\
\mathbf{( L )}\end{array}$ & $\begin{array}{r}>\mathbf{3 0 0}<=\mathbf{6 0 0 L} / \mathbf{h r} \\
\mathbf{( L )}\end{array}$ & $\begin{array}{r}>\mathbf{6 0 0 L} / \mathbf{h r} \\
\mathbf{( L )}\end{array}$ \\
\hline $0: 00$ & 15,600 & 5,550 & 2,470 & 1,490 \\
$1: 00$ & 9,590 & 1,810 & 2,620 & 4,860 \\
$2: 00$ & 7,150 & 1,280 & 2,060 & 3,510 \\
$3: 00$ & 5,730 & 1,200 & 1,950 & 5,400 \\
$4: 00$ & 7,160 & 2,760 & 1,900 & 6,690 \\
$5: 00$ & 10,690 & 2,950 & 4,610 & 7,930 \\
$6: 00$ & 22,070 & 14,380 & 8,870 & 10,530 \\
$7: 00$ & 35,120 & 37,970 & 12,960 & 25,650 \\
$8: 00$ & 44,550 & 55,540 & 21,910 & 34,630 \\
$9: 00$ & 45,830 & 65,950 & 19,380 & 28,890 \\
$10: 00$ & 41,170 & 53,270 & 17,680 & 27,000 \\
$11: 00$ & 35,580 & 43,040 & 16,090 & 23,950 \\
$12: 00$ & 31,760 & 32,900 & 8,940 & 22,750 \\
$13: 00$ & 31,740 & 23,820 & 9,650 & 20,620 \\
$14: 00$ & 30,110 & 18,920 & 12,150 & 24,490 \\
$15: 00$ & 30,790 & 21,350 & 11,830 & 30,650 \\
$16: 00$ & 30,600 & 29,130 & 18,090 & 33,180 \\
\hline $\mathbf{1 7 : 0 0}$ & 34,480 & 34,170 & 38,750 & $\mathbf{5 9 , 8 2 0}$ \\
$\mathbf{1 8 : 0 0}$ & 35,010 & 44,830 & 46,730 & $\mathbf{1 0 0 , 2 9 0}$ \\
$\mathbf{1 9 : 0 0}$ & 39,840 & 44,570 & 52,730 & $\mathbf{1 0 1 , 2 0 0}$ \\
$\mathbf{2 0 : 0 0}$ & 40,410 & 35,630 & 25,760 & $\mathbf{7 0 , 5 5 0}$ \\
\hline $21: 00$ & 38,450 & 22,570 & 16,090 & 39,690 \\
$22: 00$ & 32,910 & 16,150 & 9,150 & 21,450 \\
$23: 00$ & 24,060 & 9,190 & 5,820 & 12,060 \\
\hline & & & \\
\hline
\end{tabular}


Table 4: Tariff Model 2 water consumption distributions

\begin{tabular}{|c|c|c|c|c|}
\hline $\begin{array}{l}\text { Time of day } \\
\text { (24 hr) }\end{array}$ & $\begin{array}{r}10-100 \mathrm{~L} / \mathrm{hr} \\
\text { (L) }\end{array}$ & $\begin{array}{r}>100<=300 \mathrm{~L} / \mathrm{hr} \\
(\mathrm{L})\end{array}$ & $\begin{array}{r}>300<=600 \mathrm{~L} / \mathrm{hr} \\
(\mathrm{L})\end{array}$ & $\begin{array}{r}>600 \mathrm{~L} / \mathrm{hr} \\
(\mathrm{L})\end{array}$ \\
\hline 0:00 & 15,600 & 5,550 & 2,470 & 1,490 \\
\hline 1:00 & 9,590 & 1,810 & 2,620 & 4,860 \\
\hline $2: 00$ & 7,150 & 1,280 & 2,060 & 3,510 \\
\hline 3:00 & 5,730 & 1,200 & 1,950 & 5,400 \\
\hline 4:00 & 7,160 & 2,760 & 1,900 & 6,690 \\
\hline $5: 00$ & 10,690 & 2,950 & 4,610 & 7,930 \\
\hline 6:00 & 22,070 & 14,380 & 8,870 & 10,530 \\
\hline 7:00 & 35,120 & 37,970 & 12,960 & 25,650 \\
\hline 8:00 & 44,550 & 55,540 & 21,910 & 34,630 \\
\hline 9:00 & 45,830 & 65,950 & 19,380 & 28,890 \\
\hline 10:00 & 41,170 & 53,270 & 17,680 & 27,000 \\
\hline 11:00 & 35,580 & 43,040 & 16,090 & 23,950 \\
\hline 12:00 & 31,760 & 32,900 & 8,940 & 22,750 \\
\hline 13:00 & 31,740 & 23,820 & 9,650 & 20,620 \\
\hline 14:00 & 30,110 & 18,920 & 12,150 & 24,490 \\
\hline 15:00 & 30,790 & 21,350 & 11,830 & 30,650 \\
\hline 16:00 & 30,600 & 29,130 & 18,090 & 33,180 \\
\hline 17:00 & 34,480 & 34,170 & 38,750 & 59,820 \\
\hline 18:00 & 35,010 & 44,830 & 46,730 & 100,290 \\
\hline 19:00 & 39,840 & 44,570 & 52,730 & 101,200 \\
\hline 20:00 & 40,410 & 35,630 & 25,760 & 70,550 \\
\hline 21:00 & 38,450 & 22,570 & 16,090 & 39,690 \\
\hline 22:00 & 32,910 & 16,150 & 9,150 & 21,450 \\
\hline 23:00 & 24,060 & 9,190 & 5,820 & 12,060 \\
\hline
\end{tabular}


Table 5: Tariff Model 3 water consumption distributions

\begin{tabular}{|c|c|c|c|c|}
\hline $\begin{array}{l}\text { Time of day } \\
\text { (24 hour) }\end{array}$ & $\begin{array}{r}10-100 \mathrm{~L} / \mathrm{hr} \\
(\mathrm{L})\end{array}$ & $\begin{array}{r}>100<=300 \mathrm{~L} / \mathrm{hr} \\
(\mathrm{L})\end{array}$ & $\begin{array}{r}>300<=600 \mathrm{~L} / \mathrm{hr} \\
(\mathrm{L})\end{array}$ & $\begin{array}{r}>600 \mathrm{~L} / \mathrm{hr} \\
(\mathrm{L})\end{array}$ \\
\hline 0:00 & 15,600 & 5,550 & 2,470 & 1,490 \\
\hline 1:00 & 9,590 & 1,810 & 2,620 & 4,860 \\
\hline 2:00 & 7,150 & 1,280 & 2,060 & 3,510 \\
\hline 3:00 & 5,730 & 1,200 & 1,950 & 5,400 \\
\hline 4:00 & 7,160 & 2,760 & 1,900 & 6,690 \\
\hline 5:00 & 10,690 & 2,950 & 4,610 & 7,930 \\
\hline 6:00 & 22,070 & 14,380 & 8,870 & 10,530 \\
\hline 7:00 & 35,120 & 37,970 & 12,960 & 25,650 \\
\hline 8:00 & 44,550 & 55,540 & 21,910 & 34,630 \\
\hline 9:00 & 45,830 & 65,950 & 19,380 & 28,890 \\
\hline 10:00 & 41,170 & 53,270 & 17,680 & 27,000 \\
\hline 11:00 & 35,580 & 43,040 & 16,090 & 23,950 \\
\hline 12:00 & 31,760 & 32,900 & 8,940 & 22,750 \\
\hline 13:00 & 31,740 & 23,820 & 9,650 & 20,620 \\
\hline $14: 00$ & 30,110 & 18,920 & 12,150 & 24,490 \\
\hline 15:00 & 30,790 & 21,350 & 11,830 & 30,650 \\
\hline $16: 00$ & 30,600 & 29,130 & 18,090 & 33,180 \\
\hline $17: 00$ & 34,480 & 34,170 & 38,750 & 59,820 \\
\hline 18:00 & 35,010 & 44,830 & 46,730 & 100,290 \\
\hline 19:00 & 39,840 & 44,570 & 52,730 & 101,200 \\
\hline 20:00 & 40,410 & 35,630 & 25,760 & 70,550 \\
\hline 21:00 & 38,450 & 22,570 & 16,090 & 39,690 \\
\hline $22: 00$ & 32,910 & 16,150 & 9,150 & 21,450 \\
\hline 23:00 & 24,060 & 9,190 & 5,820 & 12,060 \\
\hline
\end{tabular}


Table 6: Tariff Model 3 financial implications to study group

\begin{tabular}{lrrr}
\hline Hours of use & No. of users & Total penalty charge (\$) & Single connection cost (\$) \\
\hline $1-50$ & 1,542 & $11,572.58$ & 7.50 \\
$51-100$ & 201 & $9,291.05$ & 46.22 \\
$101-150$ & 73 & $6,595.99$ & 90.36 \\
$151-200$ & 41 & $4,522.71$ & 110.31 \\
$201-250$ & 20 & $3,763.32$ & 188.17 \\
$251-300$ & 6 & $1,576.56$ & 262.76 \\
$301-350$ & 6 & $1,659.59$ & 276.60 \\
$351-400$ & 4 & 741.81 & 185.45 \\
$401-450$ & 2 & 345.07 & 172.54 \\
$451-500$ & 3 & $1,799.70$ & 599.90 \\
$>500$ & 7 & $4,343.08$ & 620.44 \\
\hline Totals & $\mathbf{1 , 9 0 5}$ & $\mathbf{4 6 , 2 1 1 . 4 6}$ & $\mathbf{2 4 . 2 6}$ \\
\hline
\end{tabular}

